\title{
CARACTERIZAÇÃO FÍSICA E QUÍMICA DE MELÃO DURANTE O SEU DESENVOLVIMENTO ${ }^{1}$
}

\author{
EDNA MARIA MENDES AROUCHA ${ }^{2}$, FRANCISCO ALEXANDRO DE MORAIS ${ }^{3}$, GLAUBER HENRIQUE SOUSA NUNES ${ }^{4}$, \\ HALAN VIEIRA DE QUEIROZ TOMAZ ${ }^{5}$, ALINE ELLEN DUARTE DE SOUSA ${ }^{6}$, FRANCISCO BEZERRA NETO $^{7}$
}

\begin{abstract}
RESUMO - O objetivo deste trabalho foi estudar algumas alterações físicas e químicas durante o desenvolvimento de frutos de melão de quatro cultivares. Para isto foram plantadas quatro cultivares de melão na área experimental do Departamento de Ciências Vegetais da Universidade Federal Rural do Semi-Árido - UFERSA, onde foram monitorados os períodos da antese. O delineamento experimental foi em blocos completos casualizados, com três repetições, em esquema de parcela subdividida. As parcelas foram constituídas pelas cultivares de melão ('AF 1749', Hy-Mark, Rochedo e Caipira) e as subparcelas pelas idades dos frutos (14; 21; 28; 35 e 42 dias após a antese). Quatro frutos por subparcela foram colhidos nestas idades e foram analisados quanto à massa média, firmeza, sólidos solúveis, acidez total, vitamina $\mathrm{C}$ e pH. Verificou-se interação significativa entre os fatores estudados (idades x cultivares) para massa média dos frutos, firmeza de polpa, acidez total, $\mathrm{pH}$, vitamina $\mathrm{C}$ e sólidos solúveis. A massa dos frutos, firmeza, sólidos solúveis, $\mathrm{pH}$ e Vitamina $\mathrm{C}$ aumentaram, e a acidez diminuiu durante o desenvolvimento dos frutos.
\end{abstract}

Termos para Indexação: Cucumis melo L., qualidade de frutos, idades dos frutos, antese.

\section{PHYSICAL AND CHEMICAL CHARACTERIZATION OF MELON FRUITS DURING THEIR DEVELOPMENT}

\begin{abstract}
The objective of this work was to study some physical and chemical changes during melon fruits development of four cultivars. An experiment was carried out at the experimental area of Plant Science Department of Universidade Federal Rural do SemiÁrido - UFERSA, where the anthesis period was monitored. The experimental design used was of randomized complete blocks with three replications in a split-plot scheme. To the plots were assigned the melon cultivars ('AF 1749', Hy-Mark, Rochedo e Caipira) and to the subplots were assigned the harvested fruit times (7, 14, 21, 28, 35 and 42 days after anthesis). Four fruits per subplot of each cultivar were harvested in the different fruit times, and then, they were analyzed for average weight, firmness, soluble solids, total acidity, vitamin $\mathrm{C}$ and $\mathrm{pH}$. There was a significant interaction between harvested fruit times and cultivars for average fruit weight, pulp firmness, total acidity, $\mathrm{pH}$, vitamin $\mathrm{C}$ and soluble solids. The average fruit weight, pulp firmness, soluble solids, $\mathrm{pH}$ and Vitamin $\mathrm{C}$ increased and the total acidity decreased with the melon fruit's development.
\end{abstract}

Index Terms: Cucumis melo L., fruit quality, harvested fruit times, anthesis.

\section{INTRODUÇÃO}

O melão (Cucumis melo L.) é uma olerícola de grande expressão econômica, cultivada em várias regiões do mundo devido a sua adaptação a vários solos e clima. Há grande ascensão na produção e comercialização do melão em todo mundo, sendo o Brasil um dos países com grande aumento de áreas plantadas. $\mathrm{O}$ Brasil possui uma área de 15 mil hectares dedicada ao cultivo de melão (FAO, 2006).

No País, o Nordeste destaca-se como sendo uma das principais regiões produtoras de melão, apesar de alguns fatores climáticos, como pluviosidade, desfavorecer o desenvolvimento da cultura (Mendonça et al., 2004b), atualmente contornado pela agricultura irrigada (Seagri, 2003).

$\mathrm{O}$ agronegócio do melão tornou-se fundamental para a região Nordeste devido ao grande volume de recursos e empregos gerados (Brasil, 2003a). A Chapada do Apodi, localizada entre os rios $A c ̧ u(R N)$ e Jaguaribe (CE), é responsável por cerca de $90 \%$ da produção nacional. Em 2004, 200 mil toneladas de melão foram produzidas por essa região (Brasil, 2003b). O Estado do Rio Grande do Norte é considerado o maior produtor e exportador de melão do País, com maior concentração de produção no Agropólo Mossoró-Açu, com 5.924 hectares plantados, sendo o melão amarelo a cultivar mais plantada (70\%), (IBGE, 2006).

A expansão da cultura do melão na região Nordeste devese às pesquisas científicas, às melhorias nas condições de cultivo, e à abertura de comércio. As pesquisas são desenvolvidas no sentido de promover a melhoria de cultivo visando ao aumento da produtividade (Nunes et al., 2004; Araújo et al., 2003) e à conservação da qualidade pós-colheita das frutas (Arruda et al., 2004; Mendonça et al., 2004a). Atualmente, parte da produção é exportada para a Espanha, Holanda, Inglaterra e Finlândia (Agrianual, 2001).

\footnotetext{
(Trabalho 158-06). Recebido em 10-10-2006. Aceito para publicação em: 19-04-2007.

2 Curso de Agronomia, Departamento de Agrotecnologia e Ciências Sociais, Universidade Federal Rural do Semi-Árido (UFERSA), BR 110, Km 47, 59625-900, Mossoró, RN, Brasil. E-mail: maranhota6@hotmail.com. Autor para correspondência

3 Metre em Fitotecnia na UFERSA, Mossoró, RN, Brasil. E-mail:alex-fam.biologo@ibest.com.br

${ }^{4}$ Curso de Agronomia, Departamento de Ciência Vegetais, Universidade Federal Rural do Semi-Árido (UFERSA), BR 110, Km 47, 59625-900, Mossoró, RN, Brasil. E-mail: glauber@ufersa.edu.br

${ }^{5}$ Graduando do Curso de Agronomia da UFERSA, Mossoró, RN. Bolsista de iniciação cientifica PIBIC/CNPq/UFERSA. E-mail: halanvieira@hotmail.com

${ }^{6}$ Graduando do Curso de Agronomia da UFERSA, Mossoró, RN. E-mail: aline esam@hotmail.com

Programa de Pós-Graduação em Fiototecnia, UFERSA, Mossoró, RN. E-mail: bezerra@ufersa.edu.br.
} 
Existem dois grupos de melões cultivados com características distintas, o grupo inodorus compreende os melões sem aroma acentuado, no qual se destacam os melões Amarelo e Pele de Sapo, preferidos pelos mercados interno e externo, respectivamente. O grupo cantalupensis ao contrário do inodorus, é aromático, com polpa mais adocicada, de coloração geralmente salmão ou alaranjada, são os preferidos pelo mercado externo (Silva, 2002), sendo os melões Cantaloupe, Gália, Charentais e Orange Flesh os mais conhecidos (Filgueiras et al., 2000). Os melões do grupo inodorus são mais resistentes ao transporte, quando comparado aos melões do grupo cantalupensis, devido à casca ser espessa e firme, o que lhe confere resistência à compressão (Agrov, 2005).

As informações sobre parâmetros físicos e químicos de frutas durante o desenvolvimento são importantes por auxiliarem no manejo da cultura: tais como, uso correto da irrigação e determinação do ponto de colheita. Sabe-se que, além das condições edafoclimáticas, o genótipo exerce influência no desenvolvimento de frutas e hortaliças. Tendo em vista a escassez de informações na literatura, relacionada à caracterização química durante o desenvolvimento do melão nas condições do semiárido do Nordeste brasileiro, o presente trabalho teve por objetivo avaliar as características físicas e químicas de frutos de quatro cultivares de melão: 'AF 1749' (Orange Flesh), Hy-Mark (Cantaloupe), Rochedo (Amarelo) e Caipira, produzidos no Agropólo Mossoró-Açu, durante o seu desenvolvimento.

\section{MATERIAL E MÉTODOS}

O experimento foi conduzido na Horta Didática da Universidade Federal Rural do Semi-Árido (UFERSA), MossoróRN, no período de dezembro de 2005 a fevereiro de 2006, em solo Argissolo Vermelho-Amarelo eutrófico (Embrapa, 1999). As condições ambientais de cultivo da área experimental foram as seguintes: temperatura média de $29^{\circ} \mathrm{C}$, UR de $67 \%$, precipitação 0,0 mm (Fonte: INMET) e insolação diária de 10,9 h.

O delineamento experimental usado foi em blocos completos casualizados, com três repetições, em esquema de parcelas subdivididas, sendo a parcela constituída pelas cultivares de melão ('AF 1749', Hy-Mark, Rochedo e Caipira) e a subparcela pela idade dos frutos $(14 ; 21 ; 28 ; 35$ e 42 dias após a antese). A parcela foi formada por uma linha contendo 25 plantas de meloeiro.

O preparo do solo constou de uma aração e uma gradagem, seguido de sulcamento em linhas, espaçadas de $2 \mathrm{~m}$, com profundidade de aproximadamente $20 \mathrm{~cm}$, onde foi realizada a adubação de fundação, nas seguintes quantidades calculadas por hectare: 12 ton de esterco bovino; $60 \mathrm{~kg}$ de uréia; $222 \mathrm{~kg}$ de superfosfato simples, e $70 \mathrm{~kg}$ de cloreto de potássio. Os adubos foram aplicados nos sulcos de plantio e incorporados com enxada rotativa. As adubações de cobertura foram realizadas aos 10 e 22 dias após o transplantio com uréia, totalizando, ao final do ciclo, $91 \mathrm{~kg} / \mathrm{ha}$ de uréia. As adubações foram realizadas a $5 \mathrm{~cm}$ da planta.

O transplantio foi realizado após 10 dias de semeadura em bandejas de isopropileno. O controle fitossanitário foi feito aplicando-se Conifidor ${ }^{\circledR}$, semanalmente, até 30 dias após o transplantio para combater a mosca-branca. As demais práticas culturais e manejo obedeceram às necessidades da cultura no estado.

Durante o cultivo, as flores hermafroditas foram previamente identificadas com fitas de lã coloridas. As análises para acompanhamento das alterações químicas dos melões foram realizadas em intervalos de 7 dias, a partir do $14^{\circ}$ dia após a antese, até 42 dias, onde foram avaliados nos frutos: massa média: determinada com o auxílio de uma balança digital, e os resultados foram expressos em quilograma ( $\mathrm{kg}$ ); firmeza da polpa: determinada utilizando penetrômetro, os resultados expressos em Newton (N); conteúdo de sólidos solúveis: através de refratometria, de acordo com a AOAC (1992), utilizando-se de refratômetro digital, sendo os resultados expressos em ${ }^{\circ}$ Brix; acidez total: determinada segundo a técnica estabelecida pelo Instituto Adolfo Lutz (1985), e os resultados foram expressos em porcentagem de ácido cítrico; pH: utilizou-se potenciômetro; conteúdo de vitamina C: determinada por titulometria, e os resultados expressos em $\mathrm{mg}$ de ácido ascórbico/100g de polpa.

Os dados foram submetidos à análise de variância, utilizando o software SAS (1993), e a partir dos resultados, foram ajustados modelos de regressão para a variável quantitativa através do software Table Curve (Jandel Scientific, 1991). As funções respostas foram escolhidas de acordo com os seguintes critérios: a) significância da estimativa do $\mathrm{R}^{2}$ (coeficiente de determinação); b) significância dos parâmetros das equações; c) maior valor de $\mathrm{R}^{2}$ possível, e d) uma função que represente o fenômeno em estudo. O efeito da variável qualitativa foi testado pelo teste de Tukey, ao nível de $5 \%$ de probabilidade.

\section{RESULTADOS E DISCUSSÃO}

Houve interação significativa entre cultivares de melão e idade para todas as características estudadas (Figuras 1;2;3;4; 5 e 6$)$.

Verificou-se que os melões Caipira e Rochedo apresentaram massa dos frutos superior às cultivares 'AF 1749' $\mathrm{e}$ Hy-Mark (Tabela 1 e Figura 1). Tais diferenças entre a massa dos frutos estão mais relacionadas ao comportamento específico da cultivar, como relatam Chitarra \& Chitarra (2005), do que uma resultante conseqüência de fatores edafoclimáticos.

Por outro lado, pode-se observar que a maior massa dos frutos foi atingida aos 42 dias para os melões 'AF 1749' $(1,15 \mathrm{~kg})$, Hy-Mark (1,059 kg) e Rochedo (1,57 kg), período em que é realizada a colheita desses melões na região Nordeste (Filgueiras et al., 2000). A massa superior do melão Caipira (2,95 kg),aos 35 dias, em relação aos demais, está relacionada ao fator genético; trata-se de um melão silvestre que, apesar de não ter valor comercial, é apreciado por consumidores regionais.

$\mathrm{O}$ aumento de massa dos frutos mais acentuado ocorreu a partir de 14 dias de desenvolvimento, período que compreende as fases iniciais de expansão dos tecidos dos frutos, ocorrendo acréscimos, até o final do desenvolvimento, de 64,29\%; 64,73\%; 93,75\% e 268,52\% nos melões 'AF 1749', Hy-Mark, Rochedo e Caipira, respectivamente (Figura 1 e Tabela 2). Resultados semelhantes em relação ao ganho de massa foram observados 
por Bezerra (1999), a partir de 21 dias após a antese, em melões híbridos Arava, AF 646 e XPH 13096.

O melão Caipira apresentou-se mais firme aos 35 dias quando comparado às demais cultivares (Figura 2 e Tabela 1); entretanto, aos 42 dias após a antese, apresentaram-se deteriorados. Trata-se de materiais normalmente cultivados por longos períodos de tempo por produtores locais ou utilizados em programas de melhoramento, pois possuem características desejáveis para plantios, mas não apresentam resistência ao manuseio e ao armazenamento (Lopes et al., 2003).

O aumento da firmeza durante o desenvolvimento dos frutos está associado à ação de enzimas que promovem a adesão das substâncias pécticas da parede celular das células durante a expansão dos tecidos, afirmam Stolle-Smits et al. (1999).

Pode-se notar que, inicialmente, aos 14 dias de idade dos frutos e ao longo do desenvolvimento, a firmeza foi crescente até aos 35 dias para todas as cultivares (Tabela 2). Resultados contrários foram detectados por outros autores, durante o desenvolvimento de melão, tais como crescente aumento na firmeza de melões até 21 dias (Bezerra, 1999) e 30 dias após a antese (Lester \& Dulanp,1985).

Verificou-se, a partir de 35 dias, um declínio na firmeza dos frutos da cultivar Hy-Mark e Rochedo, e aumento na firmeza dos frutos da cultivar 'AF 1749' (Figura 2). Resultados semelhantes foram detectados em melões Gold Mine por Mota et al. (2002), em que a firmeza dos frutos foi de aproximadamente $30 \mathrm{~N}$.

A explicação para o decréscimo da firmeza, segundo Kays (1991) e Awad (1993), está associada às reações químicas e bioquímicas que ocorrem durante a maturação dos frutos onde há síntese e ativação de enzimas hidrolíticas que atuam na despolimerização das substâncias pécticas que conferem rigidez à parede celular dos frutos. Segundo Araújo (2003), a principal enzima responsável pela redução de firmeza no melão é a $\hat{a}$ galactosidase. A firmeza dos melões 'AF 1749', Hy-Mark e Rochedo, analisados neste trabalho, mantiveram-se dentro do padrão para comercialização (30N), conforme especifica Alves et al. (2000).

Estatisticamente, o conteúdo de sólidos solúveis das cultivares 'AF 1749' e Rochedo foram superiores às cultivares Hy-Mark e Caipira (Tabela 1), tendo a cultivar Caipira apresentado o menor valor. Os sólidos solúveis influenciam no sabor por representar de 70 a $90 \%$ dos açúcares solúveis; é um fator tradicionalmente usado para assegurar a qualidade do melão, embora não seja considerado o único fator de qualidade (Araújo, 2006). Isto explica o valor não-comercial da cultivar Caipira.

O conteúdo de sólidos solúveis aumentou no decorrer do desenvolvimento dos frutos, tendo as cultivares 'AF 1749', HyMark e Rochedo atingido valores máximos aos 42 dias após a antese (Figura 3 e Tabela 1). Nos melões caipiras, verificaram-se valores de sólidos solúveis crescentes até 35 dias após a antese. $\mathrm{O}$ aumento no SS dos frutos durante o desenvolvimento ocorre, explicam Taiz \& Zeiger (2004), devido aos componentes químicos, oriundos da fotossíntese realizada pela planta, que correspondem principalmente aos carboidratos que são carreados para os frutos (drenos).

Os acréscimos nos valores de SS foram mais evidentes após 21 dias nos melões 'AF 1749', Hy-Mark e Rochedo, diferente do ocorrido nos melões Caipira, aos quais observaram acréscimos significativos a partir de 28 dias após a antese. Burger et al. (2002) relacionam o elevado conteúdo de sólidos solúveis durante o desenvolvimento do fruto ao aumento de açúcares, principalmente de sacarose, que ocorre aos 40 dias após a antese.

Houve diferenças nos teores de SS aos 35 e 42 dias de desenvolvimento entre cultivares, e somente os melões Rochedo, Hy-Mark e 'AF 1749' atingiram valores ideais, não inferior a 9 ${ }^{\circ}$ Brix (Alves et al., 2000) aos 35 dias após a antese, exigidos para a colheita (Figura 3 e Tabela 2).

As cultivares 'AF 1749'e Rochedo apresentaram acidez superior às cultivares Hy-Mark e Caipira (Tabela 1). Apesar de exercerem certa influência no sabor dos frutos, Menezes et al. (1998) enfatizam que a variação da acidez durante a maturação do melão tem pouco significado prático em função da baixa concentração. Verificou-se uma redução na acidez dos melões durante todo o desenvolvimento, na qual os menores valores abrangeram cerca de 10,94 mmol de $\mathrm{H}^{+} / \mathrm{kg}$ aos 42 dias após a antese, exceto nos melões 'AF 1749' (Figura 4).

Segundo Chitarra \& Chitarra (2005), a acidez dos frutos, geralmente, tende a decrescer devido à utilização dos ácidos orgânicos na atividade respiratória, que é intensa à medida que segue o crescimento e a maturação dos frutos. Para Lehninger et al. (2002), o ácido cítrico que inicia as reações do Ciclo de Krebs e outros ácidos orgânicos utilizados como intermediários nas reações podem ter seus valores reduzidos na polpa.

Os valores de $\mathrm{pH}$ das cultivares de melão aumentaram durante o desenvolvimento dos frutos, alcançando valores máximos entre 35 e 42 dias (Figura 5 e Tabela 2). Desdobrando o efeito das cultivares dentro da idade, pode-se observar que os valores de $\mathrm{pH}$ dos melões Hy-Mark foram superiores aos demais (Figura 5). Esses aumentos estão diretamente relacionados à tendência da redução da acidez dos mesmos pelo fato de os ácidos orgânicos serem degradados à medida que se segue a maturação (Chitarra \& Chitarra, 2005; Kays, 1991).

Em relação ao conteúdo de vitamina $\mathrm{C}$, ao desdobrar o efeito de cultivares dentro das idades, verificou-se que os melões Hy-Mark e Caipira apresentaram os valores superiores (Tabela 1). Observou-se acréscimo no conteúdo de vitamina $\mathrm{C}$ com o desenvolvimento dos frutos, e, independentemente da cultivar, os valores mais elevados dessa vitamina ocorreram aos 35 e 42 dias após a antese para a cultivar Caipira e demais cultivares, respectivamente (Figura 6 e Tabela 2).

$\mathrm{O}$ acréscimo nos teores de ácido ascórbico dos frutos, durante o desenvolvimento, deve-se ao aumento paralelo da glicose nos tecidos, molécula precursora da vitamina C (Lehninger et al., 2002; Davey et al., 1999). Tais aspectos podem ser observados até o ponto em que os frutos atingem a maturidade fisiológica (Chitarra \& Chitarra, 2005), pois estes valores podem oscilar ou mesmo decair durante as fases pós-colheita (Awad, 1993). 
TABELA 1 - Médias de massa dos frutos (MF), firmeza de polpa (FP), solúveis sólidos (SS), acidez total (AT), $\mathrm{pH}$ e vitamina C (VIT C) de melões ‘AF 1749', Hy-Mark, Rochedo e Caipira durante o desenvolvimento. Mossoró-RN, UFERSA, 2006.

\begin{tabular}{ccccccc}
\hline \multirow{2}{*}{ Cultivar } & \multicolumn{5}{c}{ Características avaliadas (médias) } \\
\cline { 2 - 7 } & $\begin{array}{c}\text { MF } \\
(\mathrm{Kg})\end{array}$ & $\begin{array}{c}\text { FP } \\
(\mathrm{N})\end{array}$ & $\begin{array}{c}\text { SS } \\
(\%)\end{array}$ & AT $^{1}$ & pH & VIT C $^{2}$ \\
\hline AF 1749 & $0,96 \mathrm{~b}$ & $37,64 \mathrm{~b}$ & $8,20 \mathrm{a}$ & $17,19 \mathrm{a}$ & $5,79 \mathrm{~b}$ & $14,29 \mathrm{~b}$ \\
Hy Mark & $0,89 \mathrm{~b}$ & $33,90 \mathrm{c}$ & $6,98 \mathrm{~b}$ & $14,06 \mathrm{~b}$ & $6,13 \mathrm{a}$ & $19,47 \mathrm{a}$ \\
Rochedo & $1,89 \mathrm{a}$ & $34,01 \mathrm{c}$ & $8,21 \mathrm{a}$ & $15,62 \mathrm{a}$ & $5,84 \mathrm{ab}$ & $14,33 \mathrm{~b}$ \\
Caipira & $1,96 \mathrm{a}$ & $41,00 \mathrm{a}$ & $5,28 \mathrm{c}$ & $12,50 \mathrm{c}$ & $5,81 \mathrm{~b}$ & $19,63 \mathrm{a}$ \\
\hline
\end{tabular}

* Médias seguidas de mesma letra na coluna não diferem entre si, pelo teste de Tukey, ao nível de $5 \%$ de probabilidade. ${ }^{1}$ (mmol de $\left.\mathrm{H}+/ \mathrm{Kg}\right){ }^{2}{ }^{2}$ ( $\mathrm{mg}$ vitamina $\left.C^{\prime \prime \prime} 100 \mathrm{~mL}^{-1}\right)$;

TABELA 2 - Médias de massa de frutos (MF), firmeza de polpa (FP), solúveis sólidos (SS), acidez total (AT), $\mathrm{pH}$ e vitamina $\mathrm{C}$ (VIT C) de cultivares de melões em função da idade dos frutos. Mossoró-RN, UFERSA, 2006.

\begin{tabular}{|c|c|c|c|c|c|c|c|}
\hline \multirow[t]{2}{*}{ Cultivar } & \multirow{2}{*}{$\begin{array}{l}\text { Idade do fruto } \\
\text { (dias) }\end{array}$} & \multicolumn{6}{|c|}{ Características de qualidade avaliadas } \\
\hline & & $\begin{array}{c}\mathrm{MF} \\
(\mathrm{Kg})\end{array}$ & $\begin{array}{l}\text { FP } \\
(\mathrm{N})\end{array}$ & $\begin{array}{l}\text { SS } \\
(\%)\end{array}$ & $\mathrm{AT}^{1}$ & $\mathrm{pH}$ & VITC $^{2}$ \\
\hline \multirow{5}{*}{ 'AF 1749' } & 14 & 0,567 & 32,30 & 5,01 & 17,19 & 5,43 & 6,16 \\
\hline & 21 & 0,900 & 31,70 & 5,83 & 17,19 & 5,44 & 12,14 \\
\hline & 28 & 1,080 & 38,01 & 8,40 & 17,19 & 5,55 & 15,84 \\
\hline & 35 & 1,110 & 46,05 & 10,72 & 17,19 & 5,98 & 18,30 \\
\hline & 42 & 1,160 & 40,12 & 11,05 & 15,63 & 6,55 & 19,01 \\
\hline \multirow{5}{*}{ Hy Mark } & 14 & 0,513 & 23,17 & 4,43 & 15,63 & 5,63 & 5,28 \\
\hline & 21 & 0,870 & 29,37 & 5,06 & 15,63 & 5,69 & 13,20 \\
\hline & 28 & 0,963 & 33,58 & 7,24 & 14,06 & 5,92 & 17,25 \\
\hline & 35 & 1,030 & 47,85 & 9,08 & 12,50 & 6,45 & 24,64 \\
\hline & 42 & 1,080 & 35,54 & 9,11 & 10,94 & 6,95 & 36,96 \\
\hline \multirow{5}{*}{ Rochedo } & 14 & 0,66 & 26,68 & 4,38 & 21,88 & 5,71 & 5,28 \\
\hline & 21 & 1,26 & 27,63 & 5,07 & 18,75 & 5,72 & 12,49 \\
\hline & 28 & 1,27 & 34,93 & 9,24 & 14,06 & 5,77 & 12,85 \\
\hline & 35 & 1,37 & 45,65 & 10,89 & 12,50 & 5,94 & 16,37 \\
\hline & 42 & 1,83 & 35,18 & 11,49 & 10,94 & 6,05 & 24,64 \\
\hline \multirow{4}{*}{ Caipira } & 14 & 0,70 & 19,6 & 4,00 & 15,63 & 5,31 & 5,28 \\
\hline & 21 & 1,46 & 41,42 & 4,07 & 10,94 & 5,58 & 11,44 \\
\hline & 28 & 2,73 & 49,83 & 5,35 & 10,94 & 5,90 & 13,40 \\
\hline & 35 & 2,95 & 53,14 & 7,70 & 10,94 & 6,44 & 48,40 \\
\hline
\end{tabular}

${ }^{1}$ (mmol de $\left.\mathrm{H}+/ \mathrm{Kg}\right){ }^{2}$ ( $\mathrm{mg}$ vitamina $\mathrm{C}^{\prime \prime}{ }^{\left.100 \mathrm{~mL}^{-1}\right)}$;

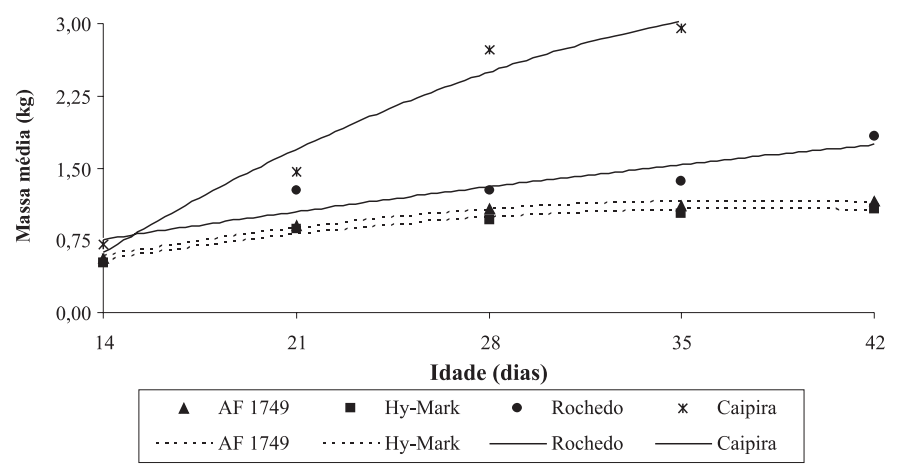

FIGURA 1 - Massa média de frutos de melões 'AF 1749', HyMark, Rochedo e Caipira, em diferentes idades, durante o seu desenvolvimento. Mossoró-RN, UFERSA, 2006.

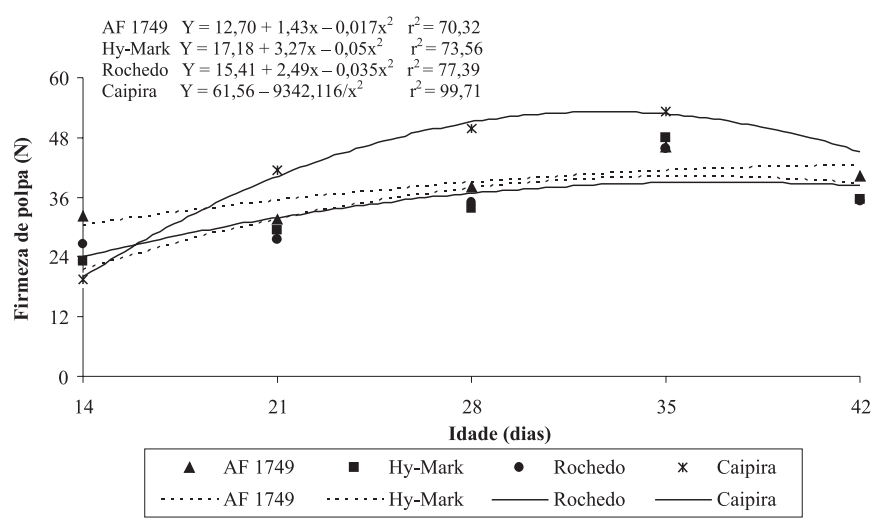

FIGURA 2 - Firmeza de polpa de melões 'AF 1749', Hy-Mark, Rochedo e Caipira, em diferentes idades, durante o seu desenvolvimento. Mossoró-RN, UFERSA, 2006.

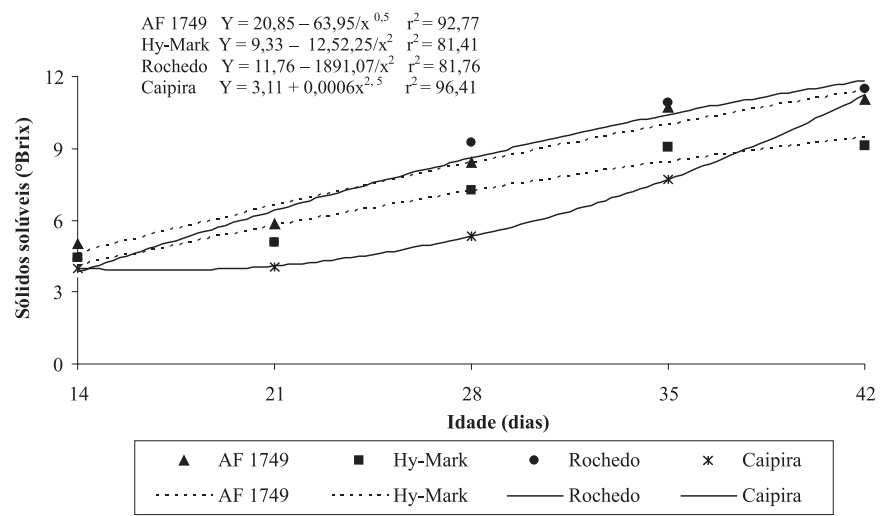

FIGURA 3 - Conteúdo de sólidos solúveis de melões 'AF 1749', Hy-Mark, Rochedo e Caipira, em diferentes idades, durante o seu desenvolvimento. Mossoró-RN, UFERSA, 2006.

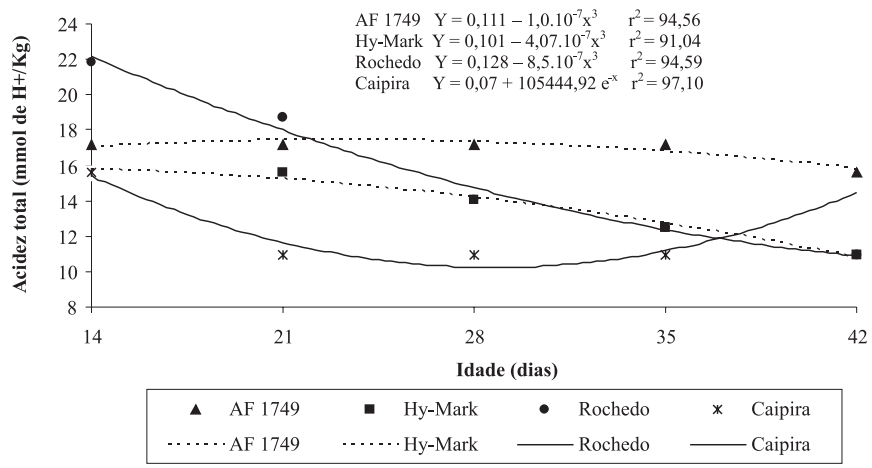

FIGURA 4 - Acidez total de melões 'AF 1749’, Hy-Mark, Rochedo e Caipira, em diferentes idades, durante o seu desenvolvimento. Mossoró-RN, UFERSA, 2006. 


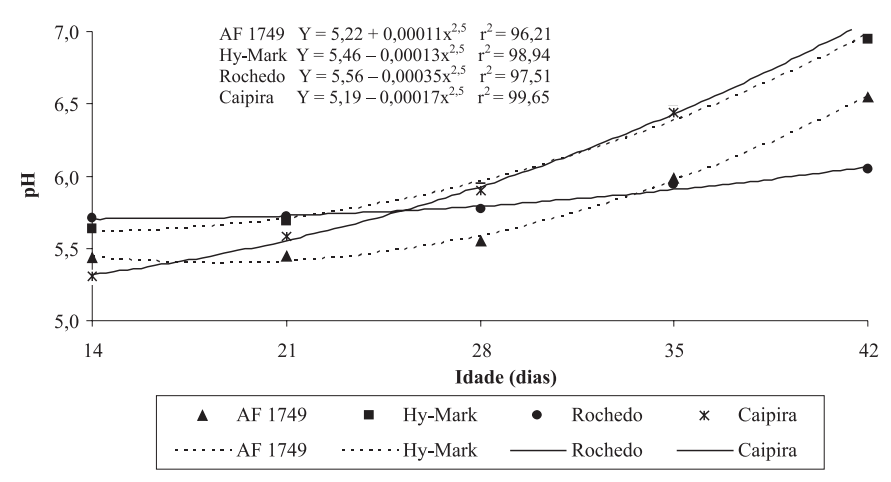

FIGURA 5 - pH de melões 'AF 1749', Hy-Mark, Rochedo e Caipira, em diferentes idades, durante o seu desenvolvimento. Mossoró-RN, UFERSA, 2006.

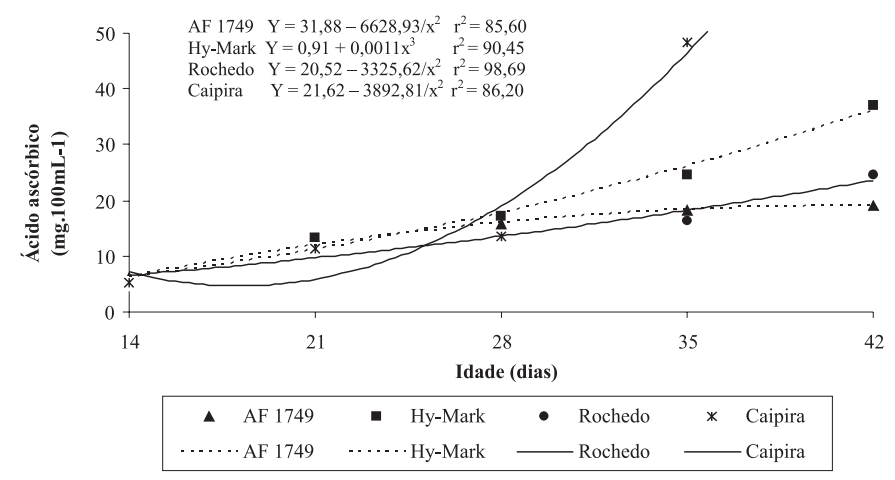

FIGURA 6 - Conteúdo de vitamina C de melões ‘AF 1749’, HyMark, Rochedo e Caipira, em diferentes idades, durante o seu desenvolvimento. Mossoró-RN, UFERSA, 2006.

\section{CONCLUSÕES}

Pelos resultados, nas condições em que o experimento foi realizado, pode-se concluir que as alterações físicas e químicas avaliadas durante o desenvolvimento das distintas cultivares de melão apresentaram comportamento semelhantes entre si em relação à massa média, firmeza de polpa, conteúdo de sólidos solúveis, acidez total, $\mathrm{pH}$ e conteúdo de vitamina $\mathrm{C}$. Ao contrário da firmeza de polpa e da acidez total, que diminuíram a partir de 35 dias após a antese, a massa média, o conteúdo de sólidos solúveis e a vitamina $\mathrm{C}$ aumentaram até 42 dias após a antese. Dentre as cultivares avaliadas, apenas o melão Caipira não apresentou conteúdo de sólidos solúveis mínimo para ser comercializado, enquanto as demais cultivares apresentaram qualidade para exportação aos 35 dias após a antese.

\section{REFERÊNCIAS}

AGRIANUAL 2002: anuário da agricultura brasileira. São Paulo: FNP Consultoria \& Comércio, 2001. 545p.
AGROV. Disponível em: < http://www. agrov.com>. Acesso em: 20 dez. 2005.

ALVES, M.Z; MENEZES, J.B; ITO, S.C.S; NASCIMENTO, S.R. de C; SALES JÚNIOR, R; ROCHA, R.H.C. Caracterização dos problemas pré e pós-colheita do meloeiro produzido em período chuvoso no Rio Grande do Norte. Revista Brasileira de Produtos Agroindustriais, Campina Grande, v.2, n.2, p.25$31,2000$.

AOAC. ASSOCIATION OF OFFICIAL AGRICULTURAL CHEMISTS. Official methods of analysis of the Association of Official Analytical Chemistry. $11^{\text {th }} \mathrm{ed}$. Washington: AOAC, 1992. 1115p.

ARAÚJO, A. P.; NEGREIROS, M.Z.; LEITÃO, M.M.V.B.R.; PEDROSA, J.F.; BEZERRANETO, F.; ESPÍNOLASOBRINHO, J.; FERREIRA, R.L.F.; NOGUEIRA, I. C. C. Rendimento de melão amarelo cultivado em diferentes tipos de cobertura do solo e métodos de plantio. Horticultura Brasileira, Brasília, v. 21, n. 1, p. 123-126, março 2003.

ARAÚJO, F. M. M. C. DE. QUALIDADE DO MELÃO TIPO ORANGE FLESH MINIMAMENTE PROCESSADO, ARMAZENADO SOB ATMOSFERA MODIFICADAATIVA. 2003. TESE (DOUTORADO EM CIÊNCIA DOS ALIMENTOS)-UNIVERSIDADE FEDERALDE LAVRAS, LAVRAS, 2003.

ARAÚJO, J. M. M. de. Eficiência do hidrorresfriamento na qualidade pós-colheita do melão Cantaloupe. 2006. $58 \mathrm{f}$. Dissertação (Mestrado) - Universidade Federal Rural do SemiÁrido, Mossoró, 2006.

ARRUDA, M.C. de; JACOMINO, A.P; SPOTO, M.H.F; GALLO, C.R; MORETTI, C.L. Conservação de melão rendilhado minimamente processado sob atmosfera modificada ativa. Ciência Tecnologia de Alimentos, Campinas, v.24, n. 1, p.053058, jan.-mar. 2004.

AWAD, M. Fisiologia pós-colheita de frutos. São Paulo: Nobel, 1993.

BEZERRA, F. M. Crescimento e desenvolvimento de melões nobres. 1999. Dissertação (Mestrado em Agronomia Fitotecnia) - Escola Superior de Agricultura de Mossoró, Mossoró, 1999.

BRASIL. Ministério da Agricultura, Pecuária e do Abastecimento. Desempenho de híbridos de melão amarelo no Ceará e no Rio Grande do Norte, no período 1999-2001. Fortaleza, $2003 \mathrm{a}$.

BRASIL. MINISTÉRIO DA INTEGRAÇÃO NACIONAL. MELÃO. BRASÍLIA, 2003B. (FRUTISÉRIES, 2)

BURGER, Y; SAAR, U; KATZIR, N; PARIS, H.S; YESELSON, Y; LEVIN, I; SCHAFFER, A.A. A Single Recessive Gene for Sucrose Accumulation in Cucumis melo Fruit. Journal of the American Society for Horticultural Science, Alexandria, v.127, n. 6, nov. 2002.

CHITARRA, M.I.F, CHITARRA, A.B. PÓS-COLHEITA DE FRUTOS E HORTALIÇAS: FISIOLOGIA E MANUSEIO. 2.ED. LAVRAS: EDITORAUFLA, 2005.

DAVEY, M.W; GILOT, C; PERSIAU, G; OSTERGAARD, J; HAN, Y; BAUW, G.C; MONTAGU, M.C.V. Ascorbate biosynthesis in arabidopsis cell suspension culture. Plant Physiology, Rockville, v. 121, n. 2, p. 535-543, out. 1999. 
EMBRAPA - Empresa Brasileira de Pesquisa Agropecuária. Centro Nacional de Pesquisa de Solos. Sistema brasileiro de classificação de solos. Brasília: EMBRAPA, 1999. 412p.

FAO. Agricultural production, prymary crpos. Disponível em $<$ http//: www.fao.com.br>. Acesso em: 30 nov. 2006.

FILGUEIRAS, H.A.C.; MENEZES, J.B.;ALVES, R.E.; COSTA, F.V.; PEREIRA, L.S.E.; GOMES JÚNIOR, G. Colheita e manuseio pós-colheita. In: ALVES, R.E. (Org.) Melão: pós-colheita. Brasília: Embrapa Comunicação para transferência de Tecnologia, 2000. cap.3, p.23-40.

IBGE. Produção Agrícola Municipal. Disponível em: http://www. ibge. gov.br/ servidor_arquivos_est/. Acesso em: 23 ago. 2006.

INSTITUTO ADOLFO LUTZ. Normas analíticas, métodos químicos e físicos para análise de alimentos. 3. ed. São Paulo: Instituto Adolfo Lutz, 1985. v. 1, 533 p.

JANDEL SCIENTIFIC. Tablecurve: curve fatting software. Corte Madeira, CA, 1991.280 p.

KAYS, J. S. Postharvest physiology of perishables plant products. New York: AVI, 1991.

LEHNINGER, A. L; NELSON, D. L; COX, M. M. Princípios de bioquímica. 2.ed. São Paulo: Savier, 2002. 1292 p.

LESTER, G.E; DULANP, J.R. Physiological changes development and ripening of 'Perlita' muskmelon fruits. Scientia Horticulturae, Amsterdam, v.26, n.4, p. 323-331, Sep. 1985.

LOPES, J.F.; CARVALHO, S.I.C.; PESSOAL, H.B.S.V. Recursos genéticos de melão e pepino na Embrapa Hortaliças. Brasília: Embrapa. 2003. 8p. (Comunicado técnico-científico, 10).

MENDONÇA, F.V.S.; MENEZES, J.B.; GOIS, V.A.; GUIMARÃES, A.A.; NUNES, G.H.S.; MENDONÇA JÚNIOR, C.F. Efeito do retardamento da colheita, na qualidade e na vida útil do melão Orange Flesh. Horticultura Brasileira, Brasília, v.22, n.1, p. 35-38, 2004a.

MENDONÇA, F.V.S.; MENEZES, J.B.; GUIMARÃES, A.A.; SIMÕES, A. do N.; SOUZA, G.L.F.M. Armazenamento de melão amarelo, híbrido RX 20094, sob temperatura ambiente. Horticultura Brasileira, Brasília, v.22, n.1 p. 76-79, 2004 b.

MENEZES, J.B.; CHITARRA, A.B.; CHITARRA, M.I.F.; BICALHO, U.O. Caracterização do melão tipo Gália durante a maturação. Horticultura Brasileira, Brasília, v.16, n.2, p.159-164, 1998.

MOTA, J.K.M; MENEZES, J.B; NUNES, G.H. de S; ROCHA, R.H.C. Qualidade e vida útil pós-colheita do melão Gold Mine produzido na época das chuvas. Revista Brasileira de Produtos Agroindustriais, Campina Grande, v. 4, n. 1, p. 2328, 2002.

NUNES, G.H.S.; SANTOS JÚNIOR, J.J.S.; ANDRADE, F.V.; BEZERRA NETO, F.; ALMEIDA, A.H.B.; MEDEIROS, D.C. Aspectos produtivos e de qualidade de híbridos de melão cultivados no agropolo Mossoró-Açu. Horticultura Brasileira, Brasília, v.22, n. 4, p.744-747, 2004.

SAS INSTITUTE INC. PROCEDURES GUIDE FOR COMPUTERS. 6ED. CARYNC, 1993. 373P.

SEAGRI. Secretaria de Agricultura e Pecuária. Produção e exportação de melão do Ceará - Safra 2003-2004. Fortaleza, 2003.

SILVA, M. C. de C. Crescimento, produtividade e qualidade do meloeiro sob diferentes níveis de salinidade da água de irrigação e cobertura do solo. 2002. Dissertação (Mestrado em Agronomia - Fitotecnia) - Escola Superior de Agricultura de Mossoró, Mossoró, 2002.

STOLLE-SMITS, T; BEEKHUIZEN, J.G.; KOK, M.T.C.; PIJNENBURG, RECOURT, K.; DERKSEN, J.; VORAGEN,A.GJ. Changes in Cell Wall Polysaccharides of Green Bean Pods during Development. Plant Physiology, Rockville, v.121, n. 2, p. 363-372, out. 1999.

TAIZ, L.; ZEIGER, E. Plant physiology. 3.ed. Sunderland, MA: Sinauer Associates, 2004. 792p. 